\title{
Prevention and management of ERCP-related complications
}

\author{
Naoki Okano, Ken Ito, Kensuke Takuma, Seiichi Hara, Yoshinori Igarashi \\ Division of Gastroenterology and Hepatology, Department of Internal Medicine (Omori), School of Medicine, Faculty of \\ Medicine, Toho University, Tokyo143-8541, Japan. \\ Correspondence to: Prof. Naoki Okano, Division of Gastroenterology and Hepatology, Department of Internal Medicine (Omori), \\ School of Medicine, Faculty of Medicine, Toho University, 6-11-1, Omorinishi, Ohta-ku, Tokyo, 143-8541, Japan. \\ E-mail:n-okano@med.toho-u.ac.jp
}

How to cite this article: Okano N, Ito K, Takuma K, Hara S, Igarashi Y. Prevention and management of ERCP-related complications. Mini-invasive Surg 2021;5:29. https://dx.doi.org/10.20517/2574-1225.2021.15

Received: 7 Feb 2021 First Decision: 17 Mar 2021 Revised: 12 Apr 2021 Accepted: 26 Apr 2021 Published: 11 Jun 2021

Academic Editor: Jean-François Rey Copy Editor: Yue-Yue Zhang Production Editor: Yue-Yue Zhang

\begin{abstract}
Endoscopic retrograde cholangiopancreatography (ERCP) and its related procedures are established as necessary and indispensable techniques in the diagnosis and treatment of bilio-pancreatic diseases. However, these procedures are associated with a high risk of complications, and caution is needed as the complications may occasionally follow a fatal course. The primary complications are pancreatitis, bleeding, perforation, and issues associated with biliary stents and lithiasis treatment. Endoscopists must perform ERCP with a strong understanding of the mechanisms of each of these complications and should be familiar with the prevention and countermeasures.
\end{abstract}

Keywords: ERCP, complications, prevention of complications, countermeasure of complications

\section{INTRODUCTION}

The complication rate of endoscopic retrograde cholangiopancreatography (ERCP)-related procedures is high among other endoscopic techniques, and complications may deteriorate into more serious conditions occasionally. Accordingly, it is necessary to be familiar with methods to prevent complications and to treat them should these occur. Here, we describe the primary complications associated with endoscopic therapies for biliary disease and discuss possible treatment approaches. 


\section{POST-ERCP PANCREATITIS}

Post-ERCP pancreatitis (PEP) can be fatal. In a systematic review that included 21 retrospective studies, the incidence rate of PEP was $3.5 \%$, the incidence rate of severe pancreatitis was $0.4 \%$, and the mortality rate was $0.11 \%^{[1]}$.

The risk factors for PEP can be patient-related or procedure-related. Patient-related risk factors include sphincter of Oddi dysfunction, female sex, history of pancreatitis, young age, non-extrahepatic bile duct dilation, non-chronic pancreatitis, and normal serum bilirubin. Procedure-related risk factors include precut sphincterotomy, pancreatic duct injection, 5 or more cannulations, pancreatic sphincterotomy, papillary balloon dilation, and endoscopic papillectomy. Furthermore, in a recent systematic review, history of PEP is proposed as a risk factor ${ }^{[2]}$. These factors must be considered while performing ERCP and other related procedures.

\section{Pancreatic stent placement}

There are many reports on the usefulness of pancreatic stent placement to prevent PEP. Mazaki et al. ${ }^{[3]}$ performed a meta-analysis of 14 randomized controlled trials and reported a significant reduction in PEP incidence in the prophylactic pancreatic stent placement group with respect to the group without stent placement. The authors concluded that pancreatic stent placement was useful in the prevention of $\mathrm{PEP}^{[3]}$. Mine et al.$^{[4]}$ also recommended prophylactic pancreatic stent placement in patients at high risk of PEP. The stents used were spontaneous dislodgement pancreatic stents ${ }^{[4]}$. Regarding stent diameters, Zolotarevsky et al. ${ }^{[5]}$ confirmed that the placement success rate was higher with $5 \mathrm{Fr}$ than that with $3 \mathrm{Fr}$ stents, but there was no difference in the PEP prevention effects according to the size. Because a $3 \mathrm{Fr}$ stent requires a 0.018 -inch guidewire, manipulations may be difficult and fluoroscopy results can be poor. With a 5Fr stent, the procedure can be performed with a small guide wire and placement takes less time. Therefore, 5 Fr pancreatic stents are recommended ${ }^{[6]}$. That said, adverse events related to pancreatic stents may occur, including damage to the pancreatic duct, inward migration of the stent, and pancreatitis due to stent occlusion $^{[7-8]}$. Because there is a risk of pancreatitis onset if the pancreatic stent does not spontaneously dislodge, the stent should be endoscopically removed in such cases ${ }^{[9]}$. Of note, approaching the pancreatic duct again to place a pancreatic stent after treating the bile duct may actually increase the risk of PEP. Pancreatic stents should be aggressively placed if a guide wire is located in the pancreatic duct, such as during pancreatic duct injection of a contrast or pancreatic guide wire cannulation. However, when only the bile duct is treated, whether to place pancreatic stents should be considered on a case-by-case basis.

\section{Wire-guided cannulation}

Because the injection of a contrast agent into the pancreatic duct may be a risk factor for PEP, wire-guided cannulation (WGC), wherein a guide wire is cannulated into the bile duct without injection of a contrast agent, was developed. It is reported to be associated with lower PEP incidence compared to conventional contrast-enhanced methods and increased rate of deep bile duct cannulation ${ }^{[10]}$. It is widely used in the Western countries as the standard procedure for bile duct cannulation. Meanwhile, a multicenter, joint randomized controlled trial in Japan showed no significant difference in the PEP incidence and deep bile duct cannulation rate between the WGC method and conventional contrast-enhanced method ${ }^{[1]}$. However, further studies will be needed in the future on the selection of cases indicated for the WGC method. If the bile duct cannulation is challenging, we recommend that a prompt switch to another method to help prevent the onset of PEP. 


\section{ERCP-ASSOCIATED BLEEDING}

Bleeding is seldom encountered in normal ERCP cases. Papillary treatments such as endoscopic sphincterotomy (EST), endoscopic papillary balloon dilation (EPBD), and endoscopic papillectomy are the primary causes of bleeding. Although a majority of the cases of bleeding are minor and bleeding may spontaneously stop during treatment ${ }^{[1]}$, it sometimes may obscure the field of view. Patient-related risk factors of post-EST bleeding include the presence of coagulopathy, undergoing anticoagulant therapy within 3 days of ERCP, and active cholangitis ${ }^{[12]}$. Anticoagulants and antiplatelet agents (APA) are associated with post-ERCP bleeding, and the American Society for Gastrointestinal Endoscopy suggests refraining from APA when undergoing $\mathrm{ERCP}^{[13]}$. Alternatively, aspirin use is considered safe and has not been reported to increase the risk of post-ERCP bleeding ${ }^{[14-16]}$. The association between thienopyridine (i.e., ticlopidine, clopidogrel, and prasugrel) and bleeding risk has not been sufficiently studied. However, it is recommended that administration of these drugs should be halted for at least 5-7 days and instead, aspirin should be administered when conducting EST, which is a high-risk procedure ${ }^{[13]}$.

In regard to the angle of EST, the direction from 11 to 12 o'clock is thought to be associated with the lowest perforation and bleeding risk. In the event of non-arterial bleeding, spraying epinephrine solution is useful. Balloon tamponade of the sphincterotomy site is also used to stop the bleeding ${ }^{[17]}$ [Figure 1]. A randomized trial of 120 patients found that prophylactic injection of hypertonic saline-epinephrine proximal to the papilla significantly reduced the risk of post-EST bleeding ${ }^{[18]}$. Hypertonic saline-epinephrine is also useful for treating intraprocedural bleeding. Thermal therapies such as high-frequency coagulation hemostasis [Figure 2] and argon plasma coagulation, cauterization hemostasis, or use of clips (hemoclips) [Figure 3] are useful. If placement of hemoclips by using a duodenoscope is challenging, use of a forward-viewing endoscope with a cap may be facilitated ${ }^{[19]}$. In either case, it is important to avoid the pancreatic orifice during thermal and mechanical applications. In case of bleeding from the papilla into the bile duct, it may not be possible to implement any of the aforementioned hemostatic techniques, and in such cases, a covered metallic stent may be effective for achieving hemostasis ${ }^{[20]}$. In addition, interventional radiology should be considered when endoscopic hemostasis is difficult. The rate of successful bleeding control with interventional radiology has been reported to be $83 \%-91 \%$ and should thus be considered prior to surgery ${ }^{[21-22]}$. In such cases, clipping at the bleeding site is a useful marker of the culprit vessel.

\section{ERCP-ASSOCIATED PERFORATION}

Treatment approaches differ according to the perforation site. According to one study, perforations can be divided into three types: guide wire perforation, papillary perforation, and duodenal perforation ${ }^{[23]}$. An alternate classification has also been proposed: duodenal perforation, papillary perforation, bile duct perforation, and retroperitoneal emphysema ${ }^{[24]}$. A majority of bile duct perforations and papillary perforations can be treated conservatively; however, most duodenal perforations require surgical treatment. Because treatment approaches differ according to the perforation site, it is important to start immediate treatment after having made a definite diagnosis in the event that a perforation has occurred.

\section{Papillary perforation, bile duct perforation}

Papillary perforation may also occur during EST, EPBD, and endoscopic papillary large balloon dilation (EPLBD), as well as during insertion of biopsy forceps and basket forceps into the common bile duct after EST and EPLBD. EST should be performed carefully so that incision is not made in an improper direction or an unnecessarily large incision is avoided. When perforation is suspected in ERCP, it is preferable to perform ERCP using $\mathrm{CO}_{2}$ gas, so that the retroperitoneal space would not be widened due to pressure from the transport gas. It is important to perform sufficient bile duct drainage and minimize the collection of intestinal juices and infection in the retroperitoneal space; this facilitates conservative treatment. For 

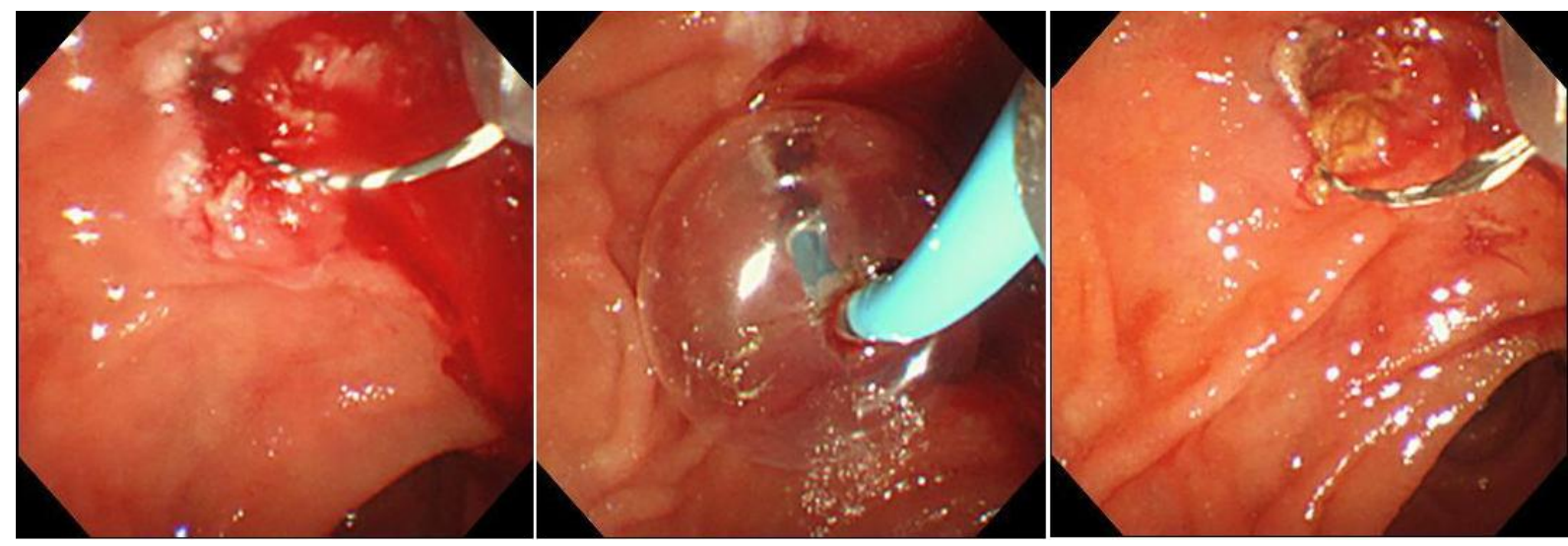

Figure 1. Hemostasis performed by balloon pressure hemostasis for bleeding after endoscopic sphincterotomy.
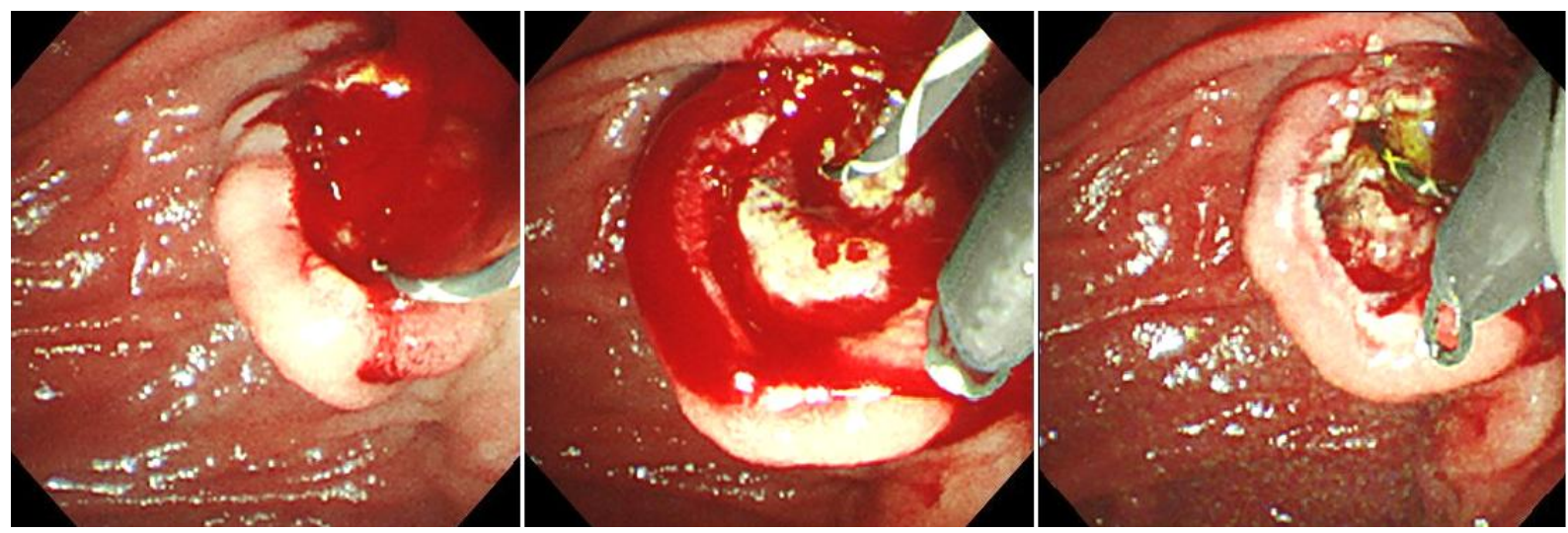

Figure 2. Hemostasis performed by Hemoclip for a vascular bleeding after endoscopic sphincterotomy.
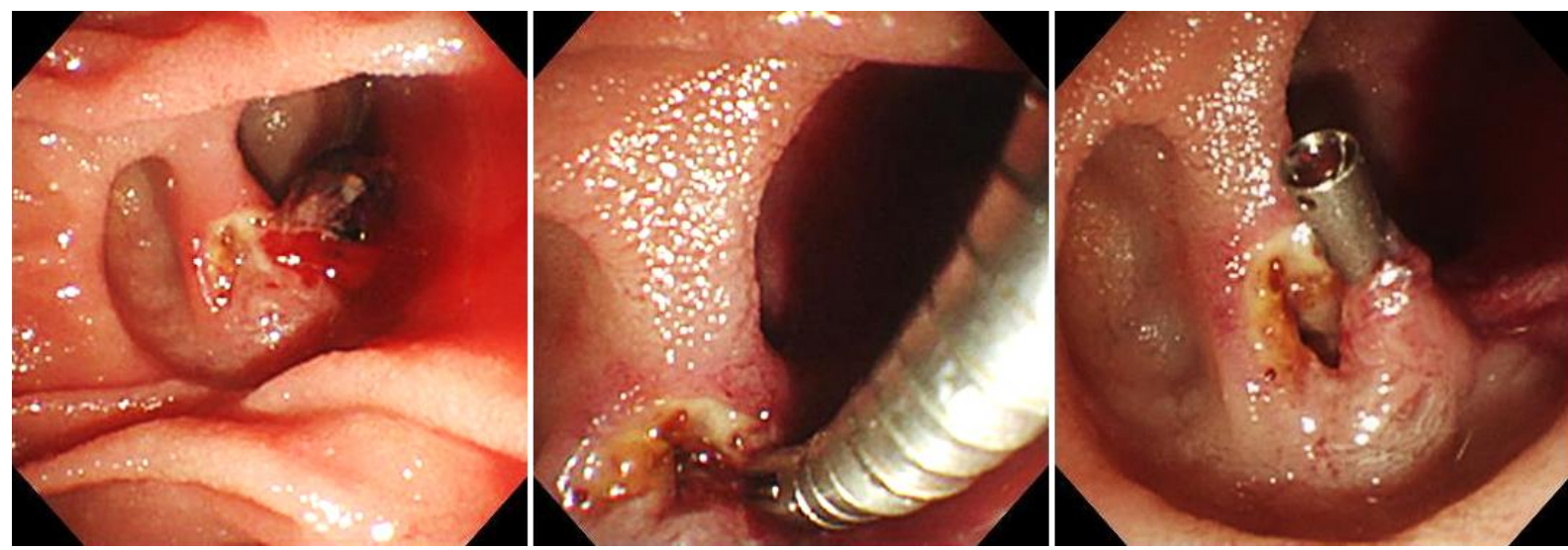

Figure 3. Coagulation hemostasis performed by Snare-tip for bleeding after endoscopic sphincterotomy.

papillary perforations, endoscopic nasobiliary drainage or biliary stent should be placed in the common bile duct, and the closure of the perforation should be attempted using clip forceps. Thereafter, a gastric tube should be placed, while conservative observation is performed by administering antibiotics and proton pump inhibitors. A papillary perforation has been treated conservatively with compression closure by 
placing a covered metallic stent ${ }^{[25]}$ [Figure 4]. Similar actions are performed in cases of papillary or bile duct perforation by a basket forceps that is associated with common bile duct stone removal. Generally, papillary perforations and bile duct perforations are caused by treatment devices, and they can usually be alleviated by bile duct drainage, gastric tube placement, and antibiotics administration ${ }^{[26]}$. Post-ERCP, free air should be checked for, as well as fluid collection in the retroperitoneal space and ascites on an abdominal computed tomography (CT). Surgical treatment should be considered in cases where progression of symptoms such as fever and abdominal pain, elevated inflammatory response, and an increasing trend of retroperitoneal space fluid collection and ascites on CT are observed.

\section{Duodenal perforation}

Duodenal perforation occurs normally during scope insertion into the descending duodenum and stretching procedures. Since adhesions of the duodenum due to previous abdominal surgeries or cancer invasion may cause perforations, it is important to perform ERCP with an awareness of preventing duodenal perforation, such as performing ERCP without the stretching procedure. Clip closure with a clip can be performed for duodenal perforations with additional conservative treatment ${ }^{[27]}$. Recently, the efficacy of over-the-scope clip for perforations during pancreaticobiliary endoscopy has been reported ${ }^{[28]}$. Duodenal perforations are usually direct injuries of the intestinal wall due to endoscopy and have large perforation hole. Hence, careful consideration is required for the indication of endoscopic closure, and surgical closure of the injury should be considered first.

\section{ERCP-RELATED TREATMENT ISSUES}

\section{Acute cholangitis}

Sepsis may occur after emergency ERCP for acute obstructive septic cholangitis. To avoid an increase in the pressure within the bile duct, ERCP should be performed initially with a small amount of contrast agent and then with endoscopic nasobiliary drainage or biliary stent drainage alone. Lithiasis treatment should be performed following cholangitis control.

Furthermore, during drainage for malignant hilar obstruction, it is preferable to not perform bile duct contrast imaging on the other side of the bile duct expected for drainage, so as to prevent cholangitis ${ }^{[2]]}$. It is important to preoperatively determine the bile duct expected for drainage in advance by CT or magnetic resonance cholangiopancreatography. Although there are reports that unilateral drainage has lower risk for cholangitis than bilateral drainage ${ }^{[30-31]}$, examination on a case-by-case basis is necessary as the obstruction state will differ depending on the case.

\section{Acute cholecystitis}

Acute cholecystitis is a complication that may occur after metallic stent placement ${ }^{[32-33]}$. The risk is particularly high in cases where a tumor extends to the cystic duct and where the cystic duct is obstructed by a covered metallic stent. Furthermore, the risk has been reported with the presence of stones in the gallbladder and the filling of the gallbladder with contrast during the examination ${ }^{[14]}$; adequate attention should be taken to prevent excessive contrast. If there is no improvement with conservative therapy, percutaneous transhepatic gallbladder aspiration or percutaneous transhepatic gallbladder drainage should be considered. In the case of cholecystitis due to a covered metallic stent, removal of the stent and replacing with a plastic stent or uncovered metallic stent should be considered.

\section{Stent migration}

Migration of plastic stents into the bile duct has been observed. Proximal stent migration was reported in approximately $5 \%$ of cases in an initial report ${ }^{[34]}$. Malignant strictures, larger diameter stents, and shorter stents were significantly associated with proximal biliary stent migration ${ }^{[34]}$. In case of proximal migration, a 

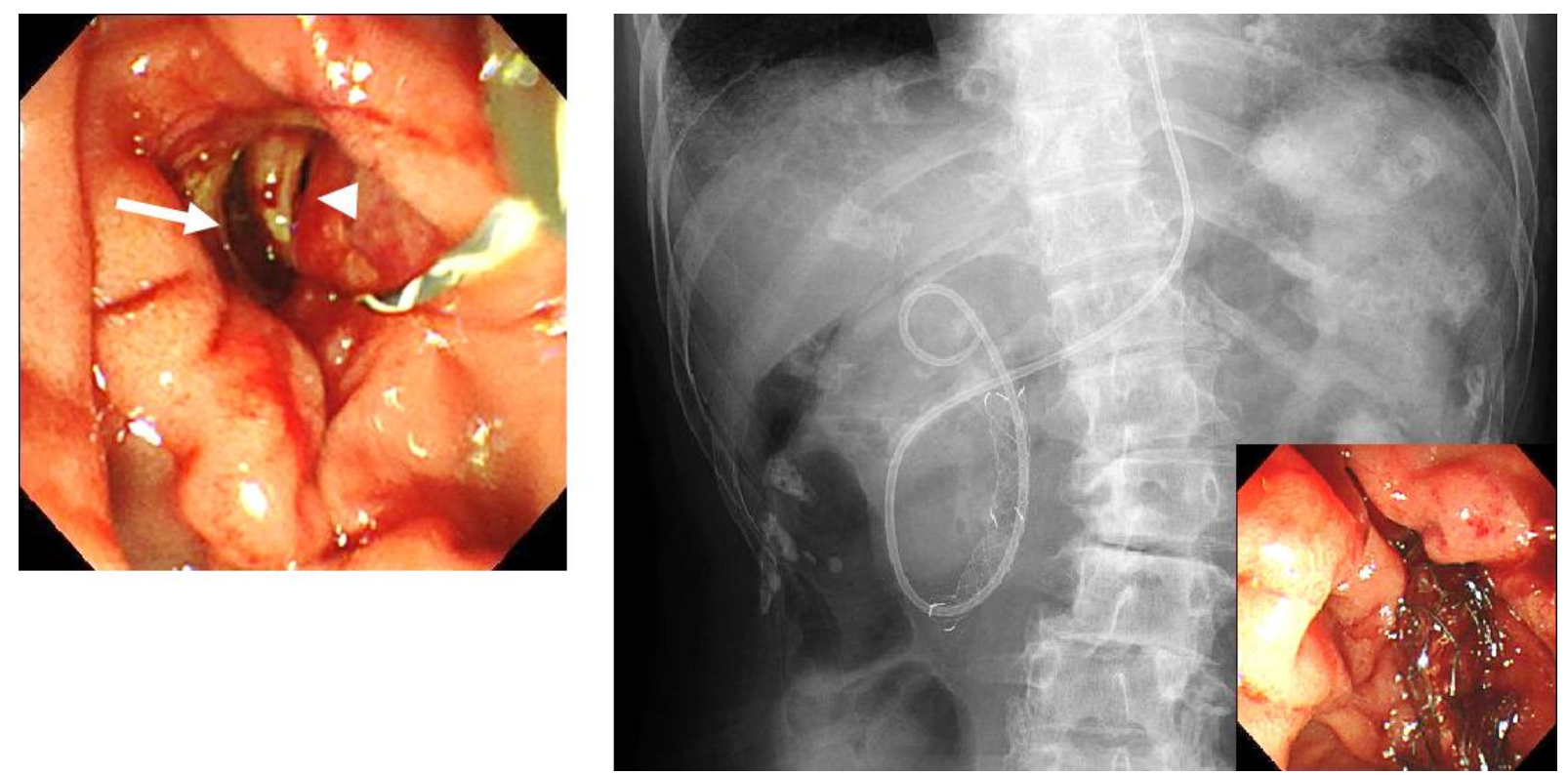

Figure 4. Case of papillary perforation after endoscopic sphincterotomy. The bile duct (arrowhead) and the perforation (arrow) were confirmed. Covered metallic stent was placed for the purpose of compression closure, and endoscopic nasobiliary drainage was performed. It subsequently conservatively alleviated the complication, and surgical treatment was avoided.

guide wire could be passed through the inside of the plastic stent, and the stent could be removed with a Soehendra Stent Retriever or a balloon catheter [Figure 5]. In cases where a guide wire could not be passed through the inside of the stent, the distal end could be grasped with a basket forceps, grasping forceps, or polypectomy snare, and the stent could recover under fluoroscopic guidance.

\section{Bile duct bleeding}

Bleeding from the tumor may occur in malignant bile duct stricture. Although this bleeding usually stops spontaneously, a covered metallic stent could be placed and pressure hemostasis could be performed in cases where bleeding from the tumor is continuous and the anemia progresses (video). In cases where hemostasis is still difficult to achieve, hemostasis by interventional radiology should be considered.

\section{LITHIASIS REMOVAL-ASSOCIATED ISSUES}

When grasping a common bile duct stone with a basket forceps, crushing the stone may be difficult due to its size or hardness, and the basket may be impossible to pull out from the papilla, thereby becoming strangulated.

When the papillary incision is small, the outside sheath of the basket forceps can be pulled off, leaving just the wire. Then, the papilla can be further dilated using a dilation balloon catheter, and it can then be removed along with the stone. If that is difficult, an endotripter may be useful. The handle of the basket catheter is cut off, and thereafter, the metal sheath of the endotripter is passed after covering the wire of the basket. In through-the-scope type thin endotripters, this action is possible without removing the scope, but for endotripters that are not through-the-scope type, the scope should be removed, and the metal sheath passed under X-ray fluoroscopic guidance. Once the metal sheath has been passed up to the basket impaction, the wire can be fixed onto the handle of the endotripter, and the stone can be crushed releasing the impaction [Figure 6]. Because basket impaction is a serious complication, it is important to always have an endotripter ready while performing lithiasis treatment. 

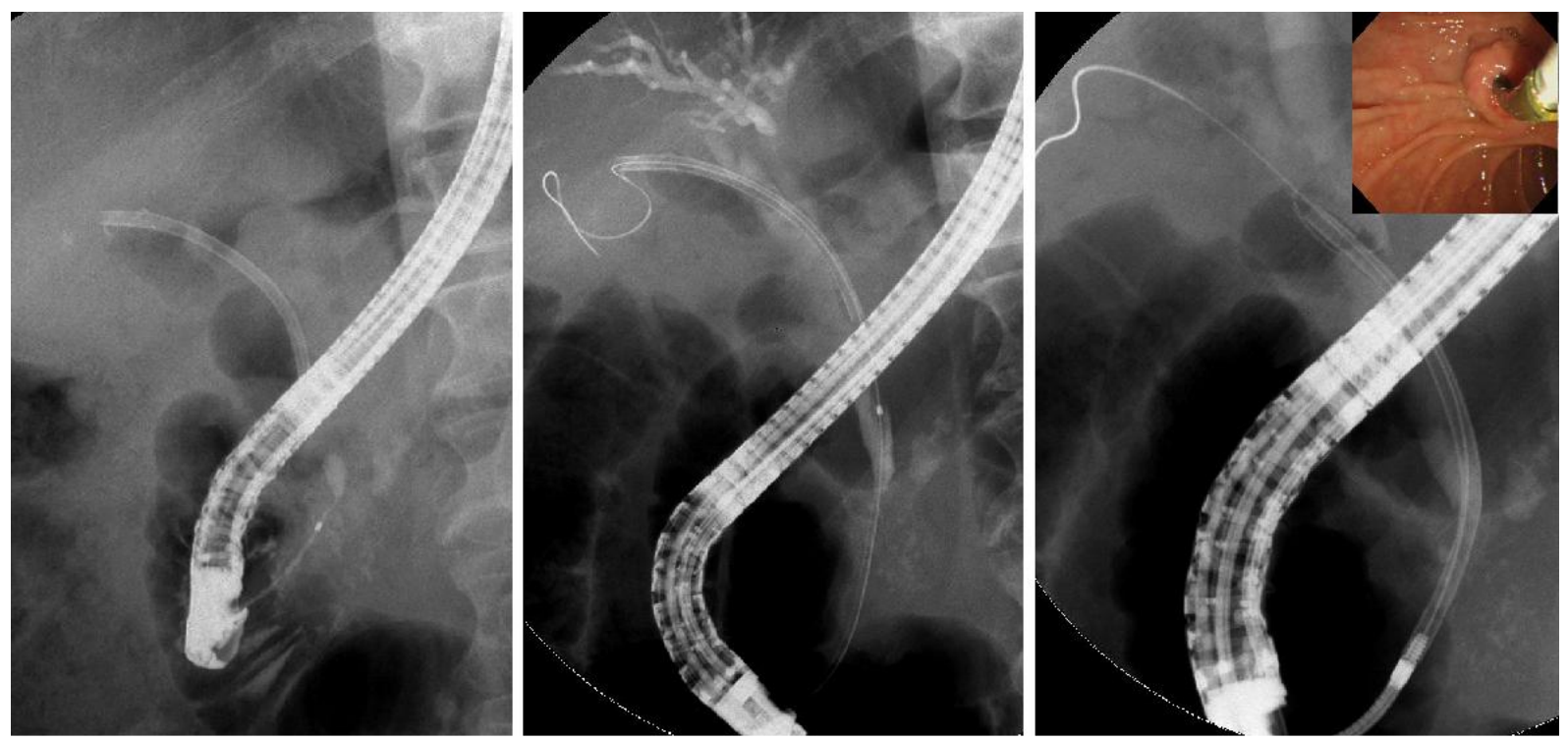

Figure 5. A bile duct plastic stent migrated into the bile duct. A contrast-enhanced cannula was guided under fluoroscopic guidance to the distal end of the plastic stent, and then a guide wire passed through the inside of the plastic stent. A Soehendra Stent Retriever was covered over the guide wire and guided under fluoroscopic guidance, the end locked onto the stent, and then withdrawn to the duodenum under fluoroscopic guidance.

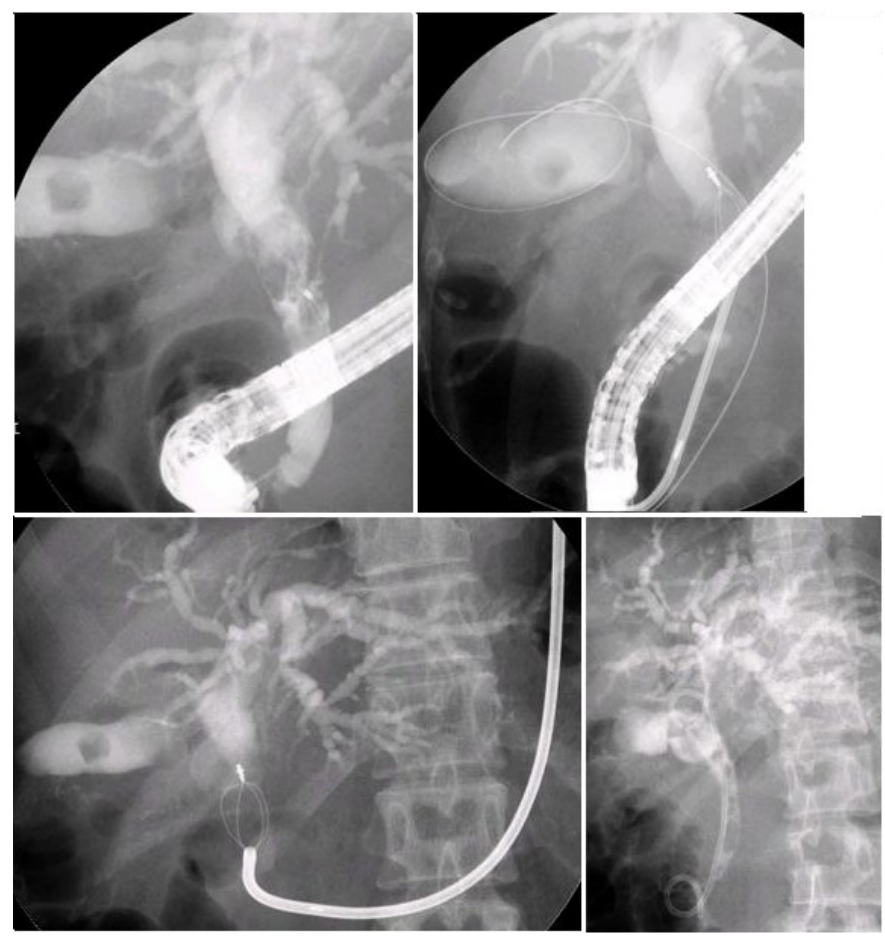

Figure 6. Although mechanical lithotripsy was attempted on a giant stone, the stone was hard and damaged the wire, and the basket was impacted. The impaction was released using an endotripter, and a tube stent was placed.

If the methods described above fail, then the impaction can be released by crushing the stone with extracorporeal shock wave lithotripsy or with electrohydraulic lithotripsy under peroral cholangioscopy. 


\section{CONCLUSION}

ERCP-related procedures are important and indispensable techniques for the diagnosis and treatment of bilio-pancreatic diseases. There are many serious complications associated with ERCP-related procedures. Endoscopists must approach ERCP with an appropriate understanding of the complications and should be familiar with the prevention and countermeasures.

\section{DECLARATIONS}

\section{Authors' contributions}

Made substantial contributions to conception and design of the study and performed data analysis and interpretation: Ito K, Igarashi $\mathrm{Y}$

Performed data acquisition, as well as provided administrative, technical, and material support: Takuma K, Hara S, Igarashi Y

\section{Availability of data and materials}

Not applicable.

\section{Financial support and sponsorship}

None.

\section{Conflicts of interest}

All authors declared that there are no conflicts of interest.

\section{Ethical approval and consent to participate}

Not applicable.

\section{Consent for publication}

Not applicable.

\section{Copyright}

(c) The Author(s) 2021.

\section{REFERENCES}

1. Andriulli A, Loperfido S, Napolitano G, et al. Incidence rates of post-ERCP complications: a systematic survey of prospective studies. Am J Gastroenterol 2007;102:1781-8. DOI PubMed

2. Pekgöz M. Post-endoscopic retrograde cholangiopancreatography pancreatitis: A systematic review for prevention and treatment. World J Gastroenterol 2019;25:4019-42. DOI PubMed PMC

3. Mazaki T, Mado K, Masuda H, Shiono M. Prophylactic pancreatic stent placement and post-ERCP pancreatitis: an updated metaanalysis. J Gastroenterol 2014;49:343-55. DOI PubMed

4. Mine T, Morizane T, Kawaguchi Y, et al. Clinical practice guideline for post-ERCP pancreatitis. J Gastroenterol 2017;52:1013-22. DOI PubMed

5. Zolotarevsky E, Fehmi SM, Anderson MA, et al. Prophylactic 5-Fr pancreatic duct stents are superior to 3-Fr stents: a randomized controlled trial. Endoscopy 2011;43:325-30. DOI PubMed PMC

6. Afghani E, Akshintala VS, Khashab MA, et al. 5-Fr vs. 3-Fr pancreatic stents for the prevention of post-ERCP pancreatitis in high-risk patients: a systematic review and network meta-analysis. Endoscopy 2014;46:573-80. DOI PubMed

7. Rashdan A, Fogel EL, Mchenry L, Sherman S, Temkit M, Lehman GA. Improved stent characteristics for prophylaxis of post-ERCP pancreatitis. Clin Gastroenterol Hepatol 2004;2:322-9. DOI PubMed

8. Smith MT, Sherman S, Ikenberry SO, Hawes RH, Lehman GA. Alterations in pancreatic ductal morphology following polyethylene pancreatic stent therapy. Gastrointest Endosc 1996;44:268-75. DOI PubMed

9. Dumonceau JM, Andriulli A, Elmunzer BJ, et al; European Society of Gastrointestinal Endoscopy. Prophylaxis of post-ERCP pancreatitis: European Society of Gastrointestinal Endoscopy (ESGE) Guideline - updated June 2014. Endoscopy 2014;46:799-815. DOI PubMed

10. Katsinelos P, Paroutoglou G, Kountouras J, et al. A comparative study of standard ERCP catheter and hydrophilic guide wire in the selective cannulation of the common bile duct. Endoscopy 2008;40:302-7. DOI PubMed 
11. Kawakami H, Maguchi H, Mukai T, et al; Japan Bile Duct Cannulation Study Group. A multicenter, prospective, randomized study of selective bile duct cannulation performed by multiple endoscopists: the BIDMEN study. Gastrointest Endosc 2012;75:362-72, 372.e1. DOI PubMed

12. Wilcox CM, Canakis J, Mönkemüller KE, Bondora AW, Geels W. Patterns of bleeding after endoscopic sphincterotomy, the subsequent risk of bleeding, and the role of epinephrine injection. Am J Gastroenterol 2004;99:244-8. DOI PubMed

13. Chandrasekhara V, Khashab MA, Muthusamy VR, et al; ASGE Standards of Practice Committee. Adverse events associated with ERCP. Gastrointest Endosc 2017;85:32-47. DOI PubMed

14. Freeman ML, Nelson DB, Sherman S, et al. Complications of endoscopic biliary sphincterotomy. N Engl J Med 1996;335:909-18. DOI PubMed

15. Hussain N, Alsulaiman R, Burtin P, et al. The safety of endoscopic sphincterotomy in patients receiving antiplatelet agents: a casecontrol study. Aliment Pharmacol Ther 2007;25:579-84. DOI PubMed

16. Hui CK, Lai KC, Yuen MF, Wong WM, Lam SK, Lai CL. Does withholding aspirin for one week reduce the risk of postsphincterotomy bleeding? Aliment Pharmacol Ther 2002;16:929-36. DOI PubMed

17. Rustagi T, Jamidar PA. Endoscopic retrograde cholangiopancreatography-related adverse events: general overview. Gastrointest Endosc Clin N Am 2015;25:97-106. DOI PubMed

18. Matsushita M, Takakuwa H, Shimeno N, Uchida K, Nishio A, Okazaki K. Prophylactic injection of hypertonic saline-epinephrine oral to the papilla for prevention of postsphincterotomy bleeding. J Clin Gastroenterol 2010;44:e167-70. DOI PubMed

19. Kubiliun NM, Adams MA, Akshintala VS, et al; United States Cooperative for Outcomes Research in Endoscopy (USCORE). Evaluation of Pharmacologic Prevention of Pancreatitis After Endoscopic Retrograde Cholangiopancreatography: A Systematic Review. Clin Gastroenterol Hepatol 2015;13:1231-9; quiz e70. DOI PubMed

20. Itoi T, Yasuda I, Doi S, Mukai T, Kurihara T, Sofuni A. Endoscopic hemostasis using covered metallic stent placement for uncontrolled post-endoscopic sphincterotomy bleeding. Endoscopy 2011;43:369-72. DOI PubMed

21. So YH, Choi YH, Chung JW, Jae HJ, Song SY, Park JH. Selective embolization for post-endoscopic sphincterotomy bleeding: technical aspects and clinical efficacy. Korean J Radiol 2012;13:73-81. DOI PubMed PMC

22. Dunne R, McCarthy E, Joyce E, et al. Post-endoscopic biliary sphincterotomy bleeding: an interventional radiology approach. Acta Radiol 2013;54:1159-64. DOI PubMed

23. Howard TJ, Tan T, Lehman GA, et al. Classification and management of perforations complicating endoscopic sphincterotomy. Surgery 1999;126:658-65. PubMed

24. Stapfer M, Selby RR, Stain SC, et al. Management of duodenal perforation after endoscopic retrograde cholangiopancreatography and sphincterotomy. Ann Surg 2000;232:191-8. DOI PubMed PMC

25. Jeon HJ, Han JH, Park S, Youn S, Chae H, Yoon S. Endoscopic sphincterotomy-related perforation in the common bile duct successfully treated by placement of a covered metal stent. Endoscopy 2011;43 Suppl 2 UCTN:E295-6. DOI PubMed

26. Lee TH, Han JH, Park SH. Endoscopic treatments of endoscopic retrograde cholangiopancreatography-related duodenal perforations. Clin Endosc 2013;46:522-8. DOI PubMed PMC

27. Lee TH, Bang BW, Jeong JI, et al. Primary endoscopic approximation suture under cap-assisted endoscopy of an ERCP-induced duodenal perforation. World J Gastroenterol 2010;16:2305-10. DOI PubMed PMC

28. Iwasa Y, Iwashita T, Uemura S, et al. The Efficacy of Over-the-Scope Clip Closure for Gastrointestinal Iatrogenic Perforation During Endoscopic Ultrasound and Endoscopic Retrograde Cholangiopancreatography for Pancreaticobiliary Diseases. Surg Laparosc. Endosc Percutan Tech 2020;30:257-62. DOI PubMed

29. Sherman S. Endoscopic drainage of malignant hilar obstruction: is one biliary stent enough or should we work to place two? Gastrointest Endosc 2001;53:681-4. DOI PubMed

30. Palma GD, Galloro G, Siciliano S, Iovino P, Catanzano C. Unilateral versus bilateral endoscopic hepatic duct drainage in patients with malignant hilar biliary obstruction: results of a prospective, randomized, and controlled study. Gastrointest Endosc 2001;53:547-53. DOI PubMed

31. Hintze RE, Abou-Rebyeh H, Adler A, Veltzke-Schlieker W, Felix R, Wiedenmann B. Magnetic resonance cholangiopancreatographyguided unilateral endoscopic stent placement for Klatskin tumors. Gastrointest Endosc 2001;53:40-6. DOI PubMed

32. Suk KT, Kim HS, Kim JW, et al. Risk factors for cholecystitis after metal stent placement in malignant biliary obstruction. Gastrointest Endosc 2006;64:522-9. DOI PubMed

33. Isayama H, Kawabe T, Nakai Y, et al. Cholecystitis after metallic stent placement in patients with malignant distal biliary obstruction. Clin Gastroenterol Hepatol 2006;4:1148-53. DOI PubMed

34. Johanson JF, Schmalz MJ, Geenen JE. Incidence and risk factors for biliary and pancreatic stent migration. Gastrointest Endosc 1992;38:341-6. DOI PubMed 